\title{
Predictability of biomass burning in response to climate changes
}

\author{
A.-L. Daniau, ${ }^{1}$ P. J. Bartlein, ${ }^{2}$ S. P. Harrison, ${ }^{1,3}$ I. C. Prentice, ${ }^{3,4,5}$ S. Brewer, ${ }^{6}$ \\ P. Friedlingstein, ${ }^{7,8}$ T. I. Harrison-Prentice, ${ }^{9}$ J. Inoue, ${ }^{10}$ K. Izumi, ${ }^{2}$ J. R. Marlon, ${ }^{11}$ \\ S. Mooney, ${ }^{12}$ M. J. Power, ${ }^{13}$ J. Stevenson, ${ }^{14}$ W. Tinner, ${ }^{15}$ M. Andrič,${ }^{16}$ J. Atanassova, ${ }^{17}$ \\ H. Behling, ${ }^{18}$ M. Black, ${ }^{12}$ O. Blarquez, ${ }^{19}$ K. J. Brown, ${ }^{20,21}$ C. Carcaillet, ${ }^{19}$ E. A. Colhoun, ${ }^{22}$ \\ D. Colombaroli, ${ }^{15}$ B. A. S. Davis, ${ }^{23}$ D. D'Costa, ${ }^{24}$ J. Dodson, ${ }^{25}$ L. Dupont, ${ }^{26}$ Z. Eshetu, ${ }^{27}$ \\ D. G. Gavin, ${ }^{2}$ A. Genries, ${ }^{19}$ S. Haberle, ${ }^{14}$ D. J. Hallett, ${ }^{28}$ G. Hope,${ }^{14}$ S. P. Horn, ${ }^{29}$ \\ T. G. Kassa, ${ }^{30,31}$ F. Katamura, ${ }^{32}$ L. M. Kennedy, ${ }^{33}$ P. Kershaw, ${ }^{24}$ S. Krivonogov, ${ }^{34}$ \\ C. Long, ${ }^{35}$ D. Magri, ${ }^{36}$ E. Marinova, ${ }^{17,37}$ G. M. McKenzie, ${ }^{24}$ P. I. Moreno, ${ }^{38}$ P. Moss,${ }^{39}$ \\ F. H. Neumann, ${ }^{40,41}$ E. Norström, ${ }^{42}$ C. Paitre, ${ }^{43}$ D. Rius,,${ }^{44,45}$ N. Roberts, ${ }^{46}$ \\ G. S. Robinson, ${ }^{47}$ N. Sasaki, ${ }^{48}$ L. Scott, ${ }^{49}$ H. Takahara, ${ }^{50}$ V. Terwilliger, ${ }^{51,52,53}$ \\ F. Thevenon, ${ }^{54}$ R. Turner, ${ }^{46,55}$ V. G. Valsecchi, ${ }^{15,56}$ B. Vannière, ${ }^{44}$ M. Walsh,,${ }^{2,57}$ \\ N. Williams, ${ }^{58}$ and Y. Zhang ${ }^{59}$
}

Received 9 November 2011; revised 17 August 2012; accepted 4 September 2012; published 23 October 2012.

\footnotetext{
${ }^{1}$ School of Geographical Sciences, University of Bristol, Bristol, UK. USA.

${ }^{3}$ School of Biological Sciences, Macquarie University, North Ryde, NSW, Australia

${ }^{4}$ QUEST, Department of Earth Sciences, University of Bristol, Bristol, UK.

${ }^{5}$ Grantham Institute for Climate Change and Division of Biology, Imperial College, Ascot, UK. USA.

${ }^{6}$ Botany Department, University of Wyoming, Laramie, Wyoming,

${ }^{7}$ Institut Pierre-Simon Laplace, Laboratoire des Sciences du Climat et de l'Environnement-UMR 1572 CNRS, Gif-sur-Yvette, France.

${ }^{8}$ College of Engineering, Mathematics and Physical Sciences, University of Exeter, Exeter, UK.

${ }^{9}$ Newton St. Cyres, Devon, UK.

${ }^{10}$ Osaka City University, Osaka, Japan.

${ }^{11}$ Department of Geography, University of Wisconsin-Madison, Madison, Wisconsin, USA.

${ }^{12}$ School of Biological, Earth and Environmental Sciences, University of New South Wales, Sydney, NSW, Australia.

${ }^{13}$ Utah Museum of Natural History and Department of Geography, University of Utah, Salt Lake City, Utah, USA.

${ }^{14}$ Department of Archaeology and Natural History, Australian National University, Canberra, ACT, Australia.

${ }^{15}$ Institute of Plant Sciences and Oeschger Center for Climate Change Research, University of Bern, Bern, Switzerland.

${ }^{16}$ Institute of Archaeology, Scientific Research Centre of the Slovenian Academy of Sciences and Arts, Ljubljana, Slovenia.

${ }^{17}$ Department of Botany, Sofia University "Sv. Kliment Ohridski", Sofia, Bulgaria.

${ }^{18}$ Department of Palynology and Climate Dynamics, Georg-August University, Göttingen, Germany.

${ }^{19}$ Centre for Bio-Archaeology and Ecology (UMR 5059 CNRS), and Paleoenvironments and Chronoecology (PALECO EPHE), Université Montpellier 2, Montpellier, France.

${ }^{20}$ Canadian Forest Service, Victoria, British Columbia, Canada.

${ }^{21}$ Department of Marine Geology and Glaciology, Geological Survey of Denmark and Greenland, Copenhagen, Denmark.
}

Corresponding author: A.-L. Daniau, CNRS, EPOC, UMR 5805, Université Bordeaux 1, Talence, France. (al.daniau@epoc.u-bordeaux1.fr)

(C)2012. American Geophysical Union. All Rights Reserved. 0886-6236/12/2011GB004249
${ }^{22}$ School of Environmental and Life Sciences, The University of Newcastle, Callaghan, NSW, Australia.

${ }^{23}$ Institute of Environment, Science and Technology, École Polytechnique Fédérale de Lausanne (EPFL), Lausanne, Switzerland.

${ }^{24}$ School of Geography and Environmental Science, Monash University, Melbourne, Victoria, Australia.

${ }^{25}$ Institute for Environmental Research, Australian Nuclear Science and Technology Organisation, Sydney, NSW, Australia.

${ }^{26}$ MARUM - Center for Marine Environmental Sciences, University of Bremen, Bremen, Germany.

${ }^{27}$ Paleoanthropology and Paleoenvironment Program, College of Natural Sciences, Addis Ababa University, Addis Ababa, Ethiopia.

${ }^{28}$ Biogeoscience Institute, University of Calgary, Calgary, Alberta, Canada.

${ }^{29}$ Department of Geography, University of Tennessee, Knoxville, Tennessee, USA.

${ }^{30}$ Seminar of Geography and Education, University of Cologne, Cologne, Germany.

${ }^{31}$ Also known as T. Gebru.

${ }^{32}$ Tokushu Kosho Gijutsu Inc., Kyoto, Japan.

${ }^{33}$ Department of Geography, Virginia Polytechnic and State University, Blacksburg, Virginia, USA.

${ }^{34}$ Institute of Geology and Mineralogy, Siberian Branch of the Russian Academy of Sciences, Novosibirsk, Russia.

${ }^{35}$ Department of Geography and Urban Planning, University of Wisconsin, Oshkosh, Wisconsin, USA.

${ }^{36}$ Dipartimento di Biologia Ambientale, Sapienza Università di Roma, Roma, Italy.

${ }^{37}$ Center for Archaeological Sciences, Katholieke Universiteit Leuven, Leuven, Belgium.

${ }^{38}$ Institute of Ecology and Biodiversity and Department of Ecological Sciences, Facultad de Ciencias, Universidad de Chile, Santiago, Chile.

${ }^{39}$ Department of Planning and Environmental Management, School of Geography, The University of Queensland, Brisbane, Australia.

${ }^{40}$ Bernard Price Institute for Palaeontology, University of the Witwatersrand, Johannesburg, South Africa.

${ }^{41}$ Forschungsstelle für Paläobotanik, University of Münster, Germany.

${ }^{42}$ Department of Physical Geography and Quaternary Geology, Stockholm University, Stockholm, Sweden.

${ }^{43}$ Département de Géographie et Centre d'Études Nordiques, Université Laval, Quebec, Canada.

${ }^{44}$ Chrono-Environment Laboratory-UMR 6249 CNRS, Université de Franche-Comté, Besançon, France.

${ }^{45}$ GEODE-UMR 5602 CNRS, Toulouse, France. 
[1] Climate is an important control on biomass burning, but the sensitivity of fire to changes in temperature and moisture balance has not been quantified. We analyze sedimentary charcoal records to show that the changes in fire regime over the past $21,000 \mathrm{yrs}$ are predictable from changes in regional climates. Analyses of paleo- fire data show that fire increases monotonically with changes in temperature and peaks at intermediate moisture levels, and that temperature is quantitatively the most important driver of changes in biomass burning over the past 21,000 yrs. Given that a similar relationship between climate drivers and fire emerges from analyses of the interannual variability in biomass burning shown by remote-sensing observations of month-by-month burnt area between 1996 and 2008, our results signal a serious cause for concern in the face of continuing global warming.

Citation: Daniau, A.-L., et al. (2012), Predictability of biomass burning in response to climate changes, Global Biogeochem. Cycles, 26, GB4007, doi:10.1029/2011GB004249.

\section{Introduction}

[2] Fire is common in most terrestrial ecosystems and has a geological history as long as that of land plants [Bowman et al., 2009]. There are potentially feedbacks from fire to climate, through pyrogenic emission of trace gases and aerosol precursors that influence atmospheric chemistry and radiative balance, as well as the feedback through $\mathrm{CO}_{2}$ emission to the global carbon cycle [Galanter et al., 2000; van der Werf et al., 2004]. Interactions between climate, vegetation and fire regimes are complicated by the influence of human activities, both through direct interventions (ignition or suppression) and as a by-product of human activities leading to landscape fragmentation and/or fuel reduction [Lavorel et al., 2007]. Interest in the processes underlying fire regimes has surged [Archibald et al., 2009; Chuvieco et al., 2008; Dwyer et al., 2000; Krawchuk et al., 2009; Le Page et al., 2007; Meyn et al., 2007; van der Werf et al., 2008] along with a growing aspiration to project how fire regimes may respond to climatic change [see, e.g., Krawchuk et al., 2009; Pechony and Shindell, 2010; Scholze et al., 2006a]. However, the direct observational record of fire (groundbased or remotely sensed) that can serve as a basis for analysis is short. Very few studies have analyzed the controls on fire regimes over periods longer than a few years or decades. There has been little consideration of how global fire might behave on centennial timescales and beyond the range of recent climates [Krawchuk et al., 2009]. This is an issue that can be addressed using sedimentary charcoal records.

[3] Sedimentary charcoal records have shown that climatedriven changes dominated regional fire records at least until the Industrial Revolution, even in long-settled regions of the world [Marlon et al., 2008; Turner et al., 2008]. Analysis of

\footnotetext{
${ }^{46}$ Earth and Environmental Sciences, School of Geography, University of Plymouth, Plymouth, UK.

${ }^{47}$ Department of Natural Sciences, Fordham College at Lincoln Center, New York, New York, USA.

${ }^{48}$ Research Institute for Humanity and Nature, Kyoto, Japan.

${ }^{49}$ Department of Plant Sciences, Faculty of Natural and Agricultural Sciences, University of the Free State, Bloemfontein, South Africa.

${ }^{50}$ Graduate School of Life and Environmental Sciences, Kyoto Prefectural University, Kyoto, Japan.

${ }^{51}$ Department of Geography, University of Kansas, Lawrence, Kansas, USA.

${ }^{52}$ Institut des Sciences de la Terre d'Orléans-UMR 6113 du CNRS/ INSU, Université d'Orléans, Orleans, France.
}

contemporary spatial patterns in southern Africa has shown that human populations can affect fire incidence both positively and negatively, with the strongest positive effects being on fire number (rather than area) in sparsely populated regions [Archibald et al., 2009]. Humans are now believed to be the principal source of ignitions in many regions of the world and possibly therefore the major control on the numbers of fires that start. But most fires are small, and the propensity for fires to become large is not dependent on ignitions. Even the well-known use of fire in recent times as an agent of deforestation in the tropics has been dependent on patterns of interannual climate variability, allowing short temporal "windows" when weather conditions are suitable for fires to spread [van der Werf et al., 2008]. There has been a great deal of speculation about the supposedly pre-eminent role of ancient human populations in determining paleo-fire regimes [e.g., Flannery, 1994; Fowler and Konopik, 2007]. However, regional scale analyses have consistently failed to show an association between human presence or activities and the amount of biomass burning as shown by charcoal records [Daniau et al., 2010a; Mooney et al., 2011; Marlon et al., 2012; Power et al., in press]. The pre-industrial charcoal record of the past 2000 yrs parallels northern hemisphere temperature changes as reconstructed from multiple high-resolution natural archives [Marlon et al., 2008] and this same pattern has been independently demonstrated for the more recent period (1350-1900), on the basis of stable isotope analyses of carbon monoxide in Antarctic ice [Wang et al., 2010; see also Prentice, 2010]. On a longer timescale, glacial periods have been characterized by less biomass burning globally than during warm intervals [Daniau et al., 2010b; Power et al., 2008]. The transition from cold glacial to warm Holocene climates was marked by a widespread

\footnotetext{
${ }^{53}$ LE STUDIUM ${ }^{\circledR}$, Loire Valley Institute for Advanced Studies, Orleans, France.

${ }^{54}$ Institut F.-A. Forel, Université de Genève, Versoix, Switzerland.

${ }^{55}$ Pedagogic Research Institute and Observatory, University of Plymouth, Plymouth, UK

${ }^{56}$ Institut des Sciences de l'Evolution de Montpellier-UMR 5554, Université Montpellier 2, Montpellier, France.

${ }^{57}$ Department of Geography, Central Washington University, Ellensburg, Washington, USA.

${ }^{58}$ Natural Resources Policy Section, NSW Department of Premier and Cabinet, Sydney, Australia.

${ }^{59}$ Institute of Botany, State Key Laboratory of Vegetation and Environmental Change, Chinese Academy of Sciences, Beijing, China.
} 
increase in fire [Power et al., 2008]. Millennial-scale variations in biomass burning are superimposed on this general trend. Abrupt warming events, such as at the end of the Younger Dryas chronozone, are characterized by peaks in charcoal and the initiation of an increasing trend in biomass burning [Marlon et al., 2009] while those associated with Dansgaard-Oeschger (D-O) events were followed by strong increases in fire with a lag no greater than 100 yrs [Daniau et al., 2007, 2010b]. On centennial and shorter timescales, drought appears to play a more important role in governing fire weather and fuel flammability [Pechony and Shindell, 2010].

[4] Explanations of the response of fire to climate change are straightforward. Increased fire in response to warming, especially in seasonally cold climates, is primarily explained by higher fuel loads resulting from increased vegetation productivity [Krawchuk et al., 2009] and a longer fire season [Westerling et al., 2006]. This mechanism may be enhanced by the influence of temperature changes on fire-supporting weather. Warming is expected to enhance fire-supporting weather through increased storm intensity and lightning ignitions [see, e.g, Price, 2009], although there is no indication that lightning ignitions are ever so low as to limit the incidence of fire [Prentice et al., 2011; Harrison et al., 2010] and through increased duration of droughts (a robust result of future climate simulations [Meehl et al., 2007]) leading to more rapid fuel drying. Warmer conditions during drought periods also accelerate fuel drying. The increase in fuel through increased productivity may be further enhanced by increased tree mortality accompanying rapid warming [Adams et al., 2009]. In dry environments, increasing precipitation leads to greater fuel loads and more fire; in wet environments, increasing precipitation leads to wetter fuels and therefore less fire [van der Werf et al., 2008], and so biomass burning is likely to be greatest at intermediate moisture levels.

[5] In order to predict how fire regimes might change in response to global warming, there is a need to express this general understanding of how climate changes affect fire regimes in quantitative terms. Specifically, we need to quantify the sensitivity of fire to changes in temperature and the water balance. Here, we present an analysis of biomass burning during the past 21,000 yrs (21 kyr), based on a global compilation of nearly 700 sedimentary charcoal records made by the Global Palaeofire Working Group (GPWG, http://gpwg.org/). The analysis documents differences in the behavior of tropical and extratropical regions of the northern and southern hemispheres (NH and $\mathrm{SH}$, respectively). We show that these patterns reflect hemispheric differences in the response of simulated temperature and moisture (using precipitation minus evaporation, P-E, as an index), to ice sheet, greenhouse gas and orbital forcing during the deglaciation and the Holocene.

\section{Methods}

\subsection{Sources of Charcoal Data}

[6] We obtained 679 sedimentary charcoal records (Figure 1a) covering part or all of the past 21,000 yrs (calibrated years BP) from a new version of the Global Palaeofire Working Group (GPWG) Global Charcoal Database (GCD version 2: http://www.gpwg.org/). The majority of these records extends up to the present-day, and includes samples representative of the post-industrial period and early twentieth century. Version 2 contains 274 more records than
Version 1, which was used for preliminary analyses of the glacial-interglacial transition, and provides a better foundation for the quantitative analyses presented here. The GCD contains charcoal records from different types of sites; we excluded records from alluvial fans and soils because these typically have poor temporal resolution, can be affected by geomorphic, sedimentological, and pedogenic processes, and may reflect extremely local fires and not the general biomass burning level. We also excluded charcoal records from archeological sites, because these reflect fuel-wood use as opposed to natural fires. However, charcoal records from marine cores are included: marine charcoal records reflect broad-scale regional changes in fire regimes [Daniau et al., 2007; Daniau et al., 2010b].

[7] There is a reasonably good geographical coverage of charcoal records from most regions of the world (Figure 1a), although the tropics are more poorly sampled than extratropical regions. The temporal coverage for the early part of the deglaciation is less good than for the Holocene, again particularly in the northern tropics. Nevertheless, the records provide a good sampling of modern climate and vegetation space (Figure 1b), and there are records from the regions of this space characterized by high levels of fire today, and thus should provide a reasonable basis for reconstructing broad-scale (semi-hemispheric-to-global) temporal changes in fire regimes.

\subsection{Treatment of Charcoal Data}

[8] Charcoal records are obtained using many different techniques and expressed using a large range of metrics [Power et al., 2008, 2010]. Typically data values can vary over many orders of magnitude among and within sites. To facilitate comparisons within and between records, we used an established protocol [Marlon et al., 2008; Power et al., 2010] for the transformation and standardization of individual records that includes (1) transforming non-influx data (e.g., concentration expressed as particles $/ \mathrm{cm}^{3}$ ) to influx values (i.e., particles $/ \mathrm{cm}^{2} / \mathrm{yr}$ ) or quantities proportional to influx, by dividing the charcoal values by sample deposition times, (2) homogenizing the variance using the Box-Cox transformation, (3) rescaling the values using a minimax transformation to allow comparisons among sites, and (4) rescaling values once more to Z-scores using a base period of 21,000 to $200 \mathrm{yrs}$ B.P. Although the base period only extends to 200 yrs B.P., the transformed records themselves extend into the twentieth century (0 yr B.P). Analyses of the impacts of each of these procedures on the records [e.g., Marlon et al., 2008; Power et al., 2010] have shown that the relationship among the untransformed, transformed and standardized series is linear or monotonic.

\subsection{Construction of Composite Charcoal Curves}

[9] Composite charcoal curves were constructed for the global, the northern and southern hemispheres and various zonal bands including the northern extratropics $\left(30-70^{\circ} \mathrm{N}\right.$; there are no records north of $70^{\circ} \mathrm{N}$ in the data set and the area of land north of $70^{\circ} \mathrm{N}$ is small), northern tropics $\left(0-30^{\circ} \mathrm{N}\right)$, southern tropics $\left(0-30^{\circ} \mathrm{S}\right)$ and southern extratropics $\left(30-60^{\circ} \mathrm{S}\right)$. The composite charcoal records were constructed using a two-stage smoothing method using locally weighted regression, or "lowess" [Cleveland and Devlin, 1988]. The lowess approach minimizes the influence of outliers, which helps 


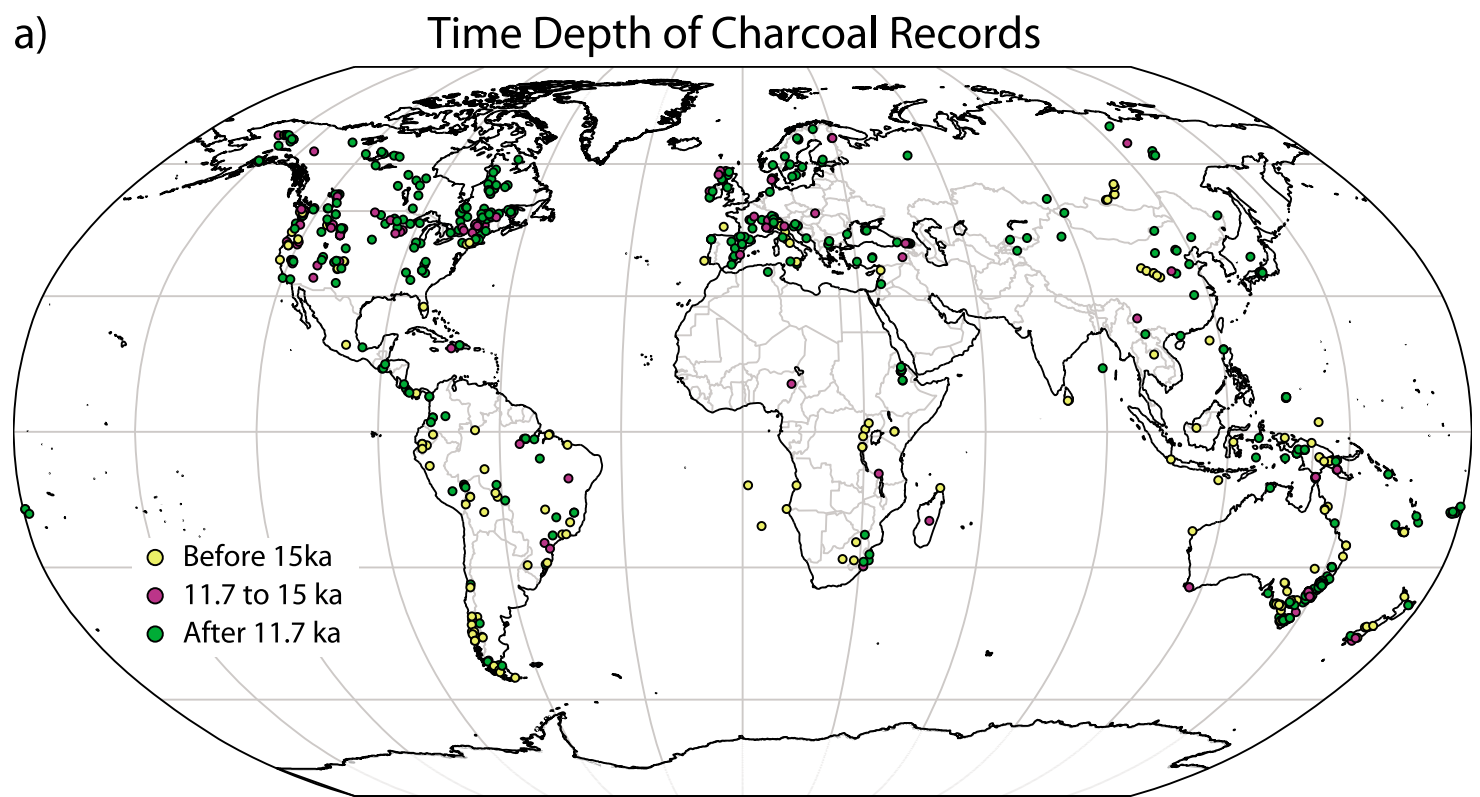

b)
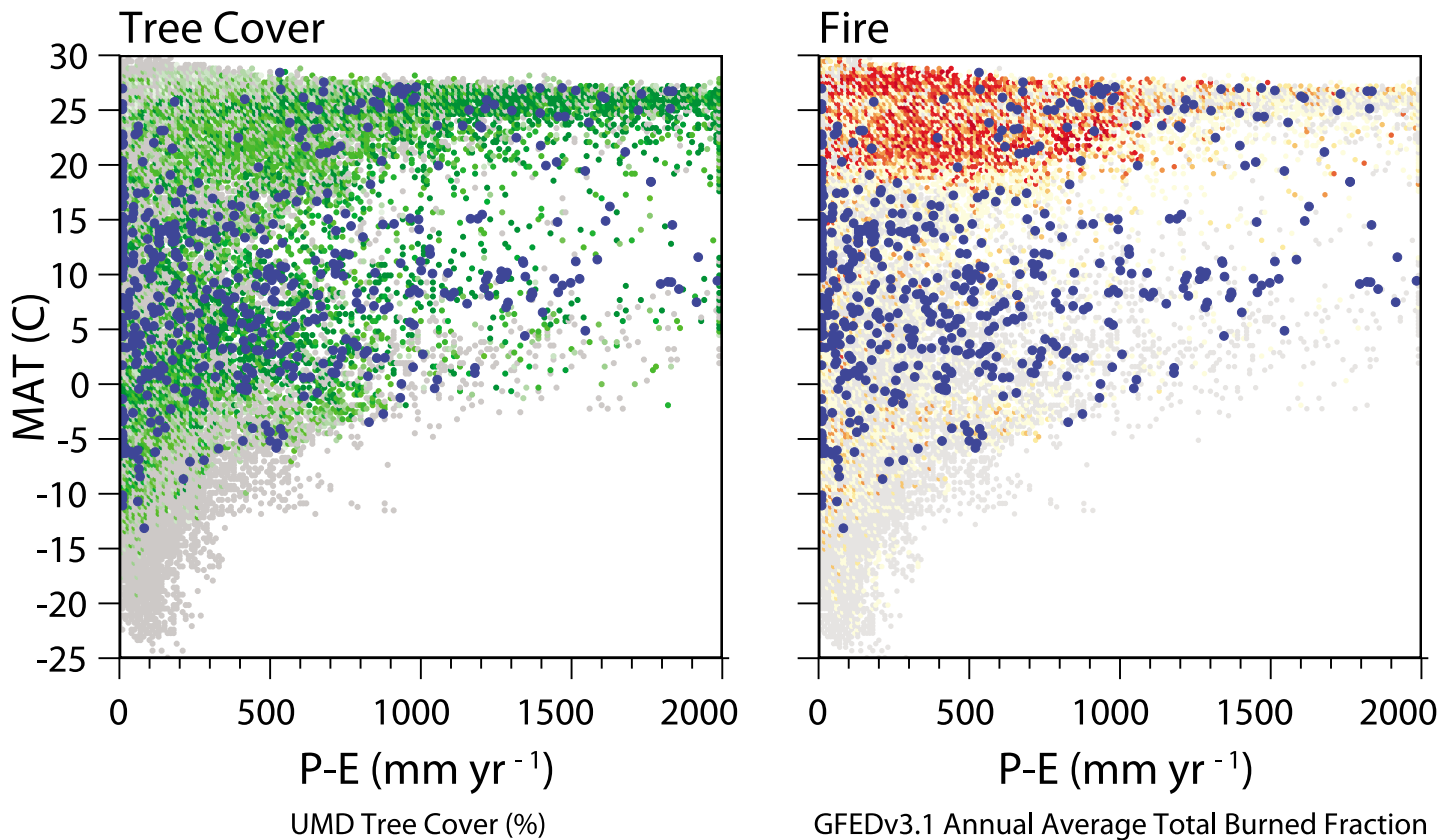

0101520253035404550556065707580

GFEDv3.1 Annual Average Total Burned Fraction \begin{tabular}{l|l|llllllll}
0 & .005 & .01 & .02 & .05 & .1 & .2 & .5 & 1
\end{tabular}

Figure 1. (a) Map showing location of charcoal sites in GCD v2, showing sites that extend back into the glacial (before ca $15 \mathrm{ka}$ ), sites that cover the rapid climate changes during the deglaciation and before the start of the Holocene (15-11.7 ka), and sites that cover part or all of the Holocene (last $11.7 \mathrm{ka}$ ). (b) Distribution of charcoal sites contributing to this analysis with respect to modern bioclimate, vegetation, and fire space. Bioclimatic space is represented by mean annual temperature (MAT) and precipitation minus evaporation (P-E) using gridded modern climate data from New et al. [2002], resampled onto a 0.5-degree grid. P-E values were calculated using the approach of Cramer and Prentice [1988].Vegetation (as represented by percent tree cover [Defries et al., 2000]) and annual average burnt fraction (derived from GFEDv3.1 [Giglio et al., 2010]) are also plotted with respect to bioclimate space for comparison.

filter noise from the charcoal data. In implementing lowess, we used a constant window width and fixed target points (in time). The lowess smoother used the customary tricube weight function, a first-degree or linear fit at each target point, and a single "robustness iteration."

[10] Individual records were first "pre-smoothed" or sampled to ensure that records with unusually high sample 


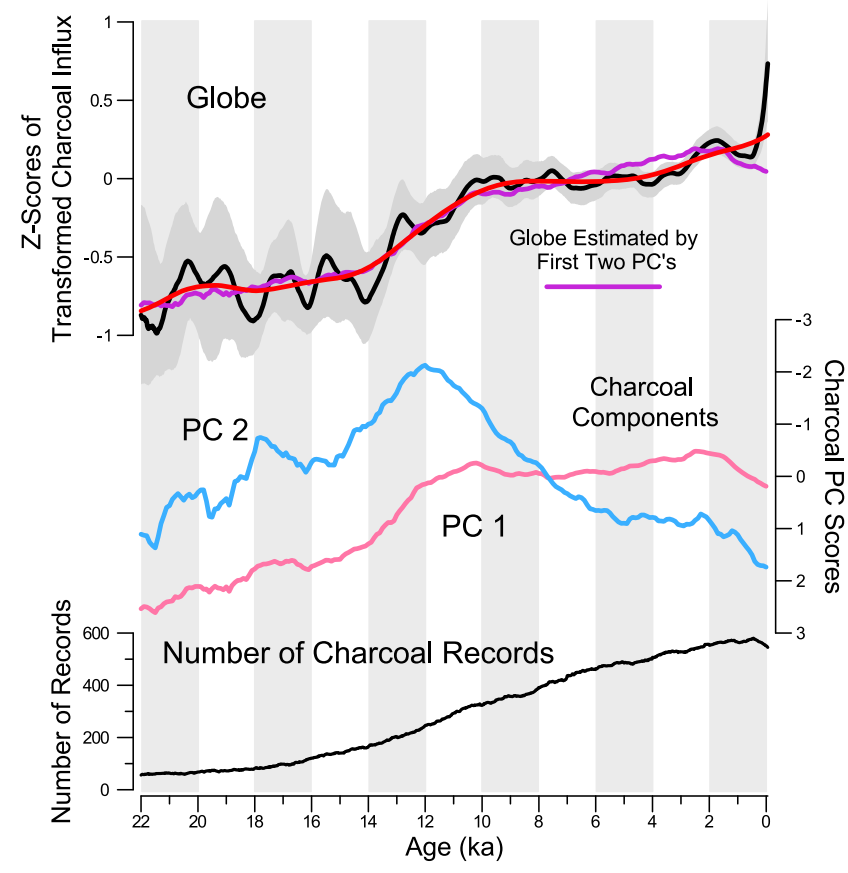

Figure 2. Reconstruction of global biomass burning over the past $21 \mathrm{kyr}$. The black curve for the charcoal series was calculated using a locally weighted regression with a window (half) width of 500 yrs, and the smooth red curve was calculated using a locally weighted regression with a window (half) width of 2000 yrs. The bottom panel shows the results of PCA, showing the time series of the first two components from the charcoal data. Together, the first two components account for about $75 \%$ of the overall variance of the charcoal data, and this is illustrated by the irregular purple curve on the top panel of the figure, plotted over the global charcoal composite curve. The number of charcoal records contributing to the global reconstruction is shown in the bottom panel.

resolution (e.g., sub-annual or annual resolution) did not have a disproportionate influence in the composite record. The window (half) width for this step was $10 \mathrm{yrs}$, with a fit of order 0 (i.e., a locally weighted mean) and a robustness parameter of 0 , thus including all data values that fall within the window when calculating the local mean. If no points fell within a particular window, no interpolation was performed, thereby avoiding pseudo-replication. Lowess was then used to create the composite charcoal curves for a particular set of records using both a 500-yr moving window and a $2000-y r$ moving window. The smooth curves shown here were constructed by determining fitted values at 20 -yr intervals. Confidence intervals for each composite curve were generated by bootstrap re-sampling with replacement of individual sites (rather than individual samples) over 1000 replications. Bootstrap confidence intervals for each target point were taken as the 2.5th and 97.5th percentiles of the 1000 fitted values for that target point.

\subsection{Analyses of the Charcoal Data: Principal Components Analysis}

[11] To explore the variability in the data set, we performed principal components analysis (PCA) on the transformed charcoal data (Figure 2). The length and sampling resolution of the individual charcoal records varies, as does the resolution of the individual age models, and so the collection of charcoal records is incomplete from the perspective of the whole interval between $21 \mathrm{ka}$ and present. We therefore used an approach that tolerates incomplete data and is implemented in the pcaMethods library [Stacklies et al., 2007] from the R-based Bioconductor project [Gentleman et al., 2004; $R$ Development Core Team, 2010]. In particular, we used the Probabilistic PCA (PPCA) algorithm, because it makes few assumptions about the data being analyzed, and potential violations of these assumptions is mitigated by the transformation protocol we follow.

[12] The PCA was performed on lowess-estimated z-scores averaged for 500 -yr intervals at 100 -yr timesteps, on records that were at least $50 \%$ complete. We experimented with the "completeness" criterion, as well as with the number of components, and found that the first few components are robust with respect to these variations in the analysis design. As is the case with "standard" PCA, the analysis produces a set of component scores that show the temporal variability in the basic patterns represented by the components and statistics that measure their contribution to the overall variance of the records.

\subsection{Climate Data}

[13] We used results from a transient ECBILT-CLIO simulation of the past 21,000 yrs (Sim2b1) [Timm and Timmermann, 2007]. The ECBILT-CLIO model (version 3) is a fully coupled three-dimensional atmosphere-ocean-sea ice model though of comparatively low resolution (64 cells in longitude by 32 cells in latitude). The sensitivity of ECBILTCLIO to $\mathrm{CO}_{2}$ concentration is at the low end of the range exhibited by state-of-the-art coupled climate models [Renssen et al., 2005]. In the Sim $2 b 1$ simulation, the climate sensitivity was therefore increased to take this into account. The transient simulation was started from an equilibrium simulation of the Last Glacial Maximum (LGM, ca $21 \mathrm{kyr}$ ) and run by changing orbital forcing, land-sea-ice distribution and topography, and greenhouse gas concentrations in a realistic way. The simulation does not reproduce forced millennial-scale variability during the past $21 \mathrm{kyr}$. The forcings associated with abrupt climate changes during the deglaciation are not well known, and no attempt was made to include them as drivers of the transient simulation.

[14] The model output consists of annual values of individual climate variables on a grid of 64 cells in longitude by 32 cells in latitude. We only consider ice-free land grid points in making global, hemispheric or zonal averages of the climate variables for use in regressions with charcoal data (i.e., Figures 3 and 4 and Figures S1 and S2 in the auxiliary material). ${ }^{1}$ However, in examining the latitudinal variations of summer, winter and annual temperatures (Figure S2) we consider all grid points. Preliminary analyses of the model output showed that summer and winter temperatures are highly correlated on long timescales $(r=0.78$; $\mathrm{p}<0.001$ ), so we use mean annual temperature as a parsimonious representation of overall warmth. Annual temperature and precipitation are also highly correlated $(\mathrm{r}=0.94$;

\footnotetext{
${ }^{1}$ Auxiliary materials are available in the HTML. doi:10.1029/ 2011 GB004249.
} 


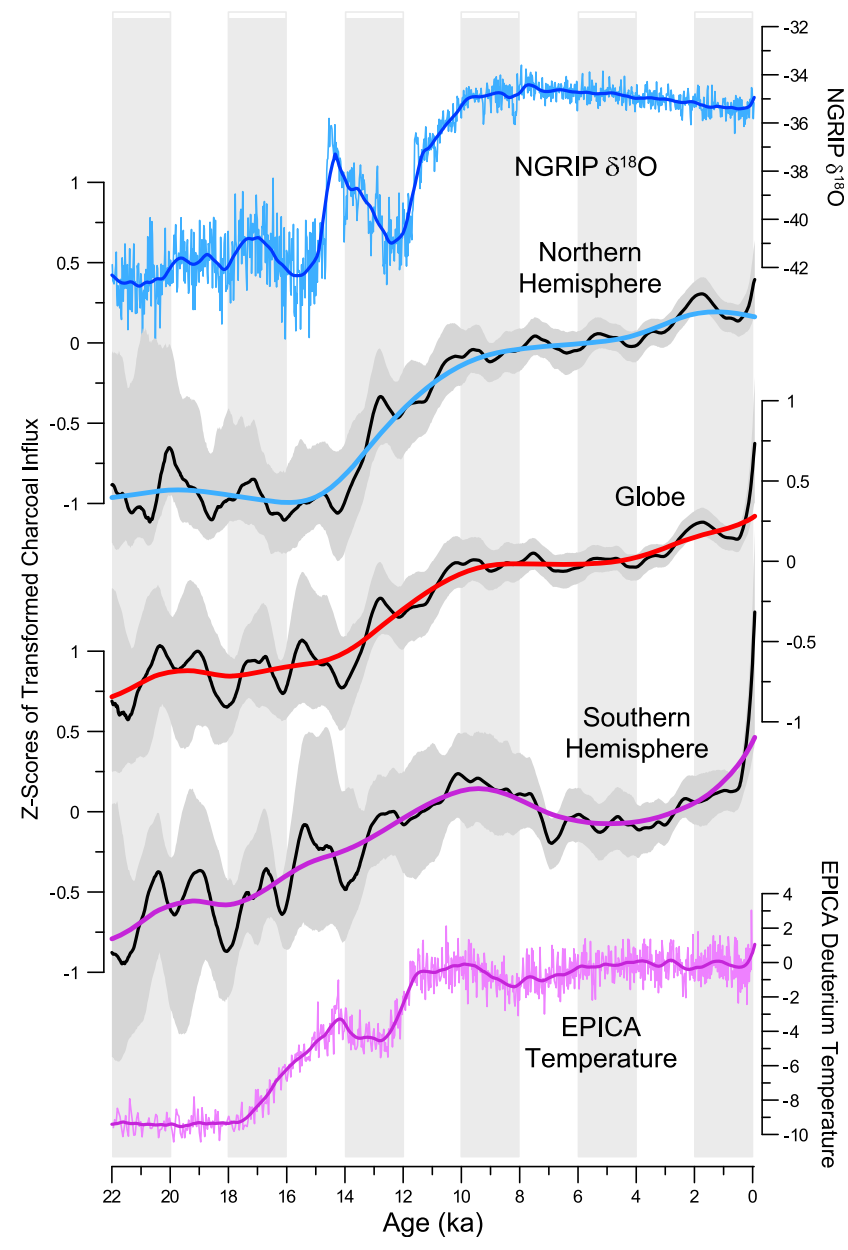

Figure 3. Reconstructions of biomass burning and climate over the past $21 \mathrm{kyr}$. Reconstructions of biomass burning are shown for the global data set and separately for the $\mathrm{NH}$ and the $\mathrm{SH}$, with confidence intervals based on bootstrap resampling by site (see the auxiliary material). The NGRIP $\delta^{18} \mathrm{O}$ record from Greenland, a proxy for northern high latitude temperature [Johnsen et al., 2001] and the EPICA (EDC) deuterium excess temperature proxy record from Antarctica [Jouzel et al., 2007], are shown for comparison. The ice core data are presented here on the GICC05 age scale, and smoothed using a 500-yr window for comparison with the charcoal records. The black curves for the charcoal series were calculated using a locally weighted regression with a window (half) width of $500 \mathrm{yrs}$, and the smooth colored curves for all series were calculated using a locally weighted regression with a window (half) width of 2000 yrs. The ice core series also show a smoothed curve using a 500-yr window.

$\mathrm{p}<0.001$ ), while changes in P-E and MAT showed different patterns through time (see Figure S1 and S2). The use of P-E as a moisture index is also consistent with our understanding of the mechanism by which moisture influences fire, namely through the dryness of the fuel load. Because the amplitude of the $21 \mathrm{ka}$ to present climate changes varies with latitude, the climate data were expressed as standardized deviation (z-scores) from the mean values over the past $21 \mathrm{kyr}$.

\subsection{Burnt Area Data}

[15] Data on burnt area was derived from the GFEDv3.1 data set [Giglio et al., 2010; http://www.falw.vu/ gwerf/ GFED/index.html). This product contains gridded monthly burnt area over the period from July 1996 to December 2008 at $0.5^{\circ}$ resolution derived from remotely sensed observations from multiple satellites.

\subsection{Development of Generalized Additive Models}

[16] We developed generalized additive models (GAMs) [Hastie and Tibshirani, 1990; Wood, 2006] to explore the relationship between the temporal and spatial variations in fire and climate. This particular statistical modeling framework permits the development and visualization of smooth functions that link a particular response (here the charcoal data or the contemporary remotely sensed burnt-area data) to a small number of explanatory variables (here MAT and P-E

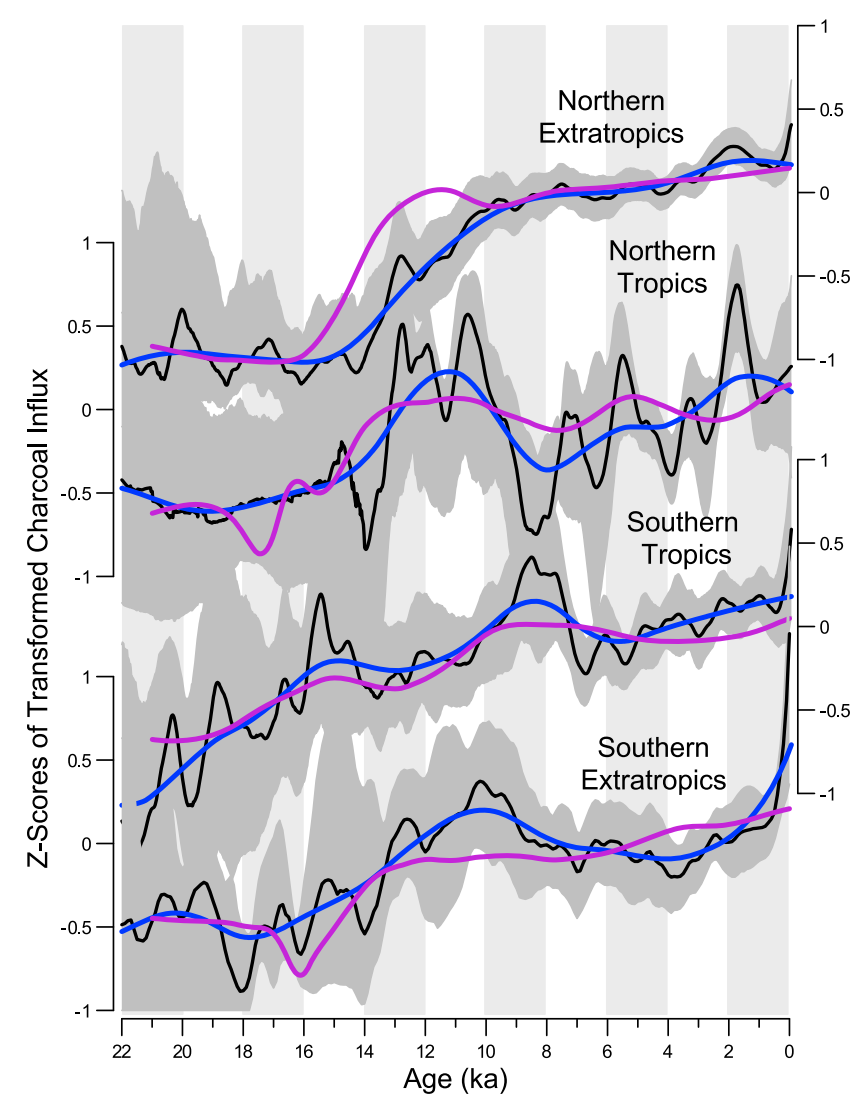

Figure 4. Observed and predicted zonal changes in biomass burning over the past $21 \mathrm{kyr}$. Composite charcoal curves are shown for the northern extratropics $\left(30^{\circ} \mathrm{N}-90^{\circ} \mathrm{N}\right)$, northern tropics $\left(0-30^{\circ} \mathrm{N}\right)$, southern tropics $\left(0-30^{\circ} \mathrm{S}\right)$ and southern extratropics $\left(30^{\circ} \mathrm{S}-90^{\circ} \mathrm{S}\right)$ with confidence intervals based on bootstrap resampling by site. The black curves for all series were calculated using a locally weighted regression with a window (half) width of 500 yrs and the blue curves for all series were calculated using a locally weighted regression with a window (half) width of 2000 yrs. The purple lines show values of charcoal predicted using the GAM fit using zonally averaged charcoal values and similarly averaged temperature and P-E over land as simulated by the ECBILT-CLIO model. 

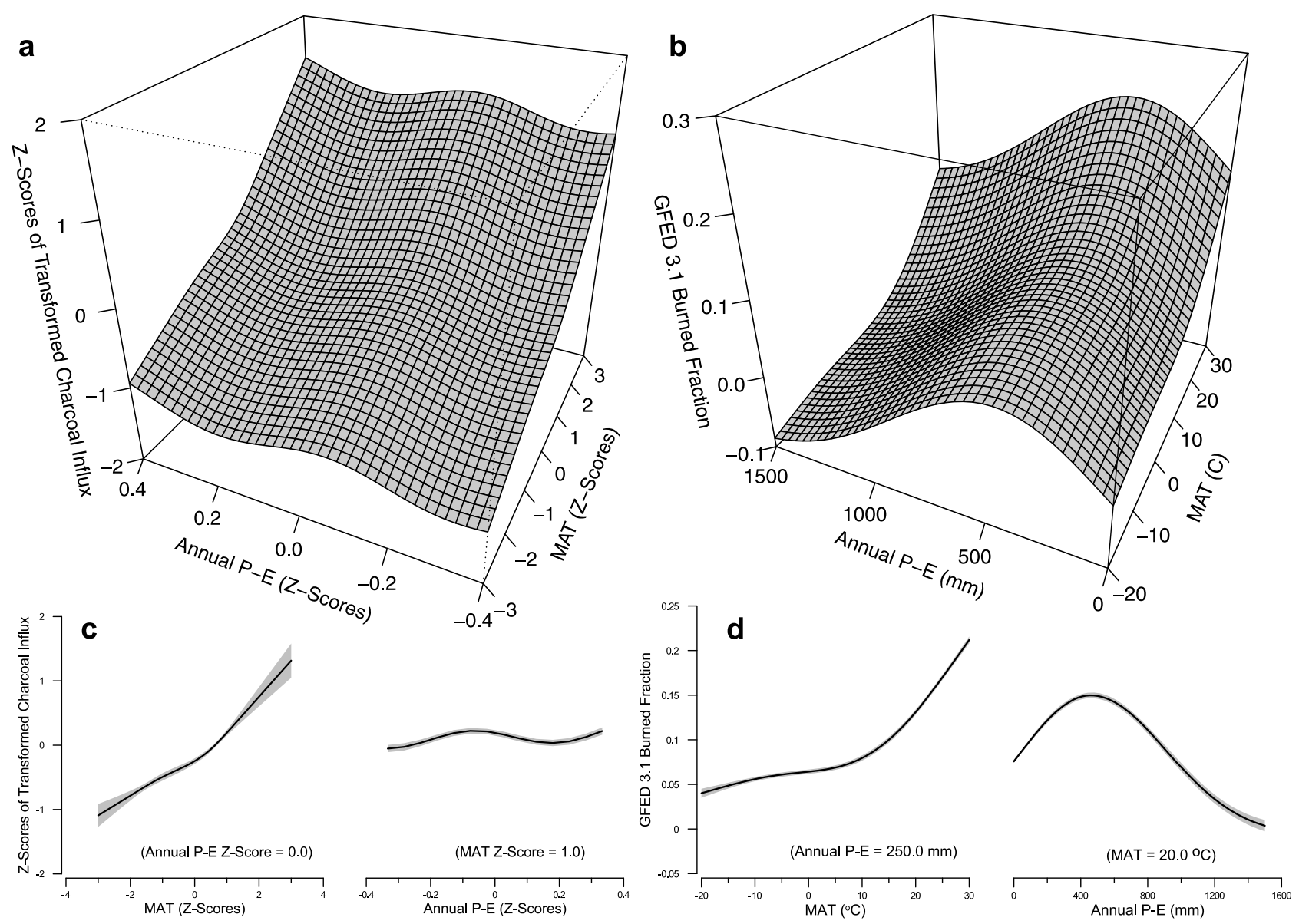

Figure 5. Relationships between climate and fire at a global scale derived (a) from the GAM analysis of charcoal and paleoclimatic data and (b) from contemporary remotely sensed burnt-area data from GFEDv3.1 [Randerson et al., 2007] and observed climate data from the CRU CL 2.0 data set [New et al., 2002]. In both analyses, biomass burning increases monotonically with temperature and is maximized at intermediate levels of P-E. The curves plotted below each surface (Figures 5c and 5d) show cross-sections through the surfaces and also show the standard errors of the fitted surface.

from paleoclimatic simulations or contemporary observations). The charcoal data and burnt-area data are both relatively noisy, and alternative methods for developing response surfaces (such as polynomial functions fit by ordinary least squares) have some undesirable properties when applied in the present context. In particular, when made sufficiently flexible (by increasing the order of the polynomial), fitted surfaces are prone to be overly influenced by individual extreme data values. The GAM-fitted surfaces can also be overly influenced by individual data points, but this can be controlled explicitly by constraining the smoothness of the fitted surface.

[17] We used the R package mgcv [Wood, 2006] to fit surfaces that display the responses of the charcoal composite curves and of the contemporary burnt-area data (Figure 5) to variations in MAT and P-E. We employed the tensor-product smoother with thin-plate regression splines because our climate data have different units of measurement, and the resulting surfaces would likely be anisotropic. Initial exploration of univariate and bivariate fits in the various data sets indicated initial basis dimensions of 4 and 8 for MAT and P-E, respectively; higher values lead to surfaces that are lumpy or "overfitted," while lower values lead to surfaces that may be too smooth. In the present context, where interpretation of the relationship is the goal (as opposed interpolation among the data points), we prefer smoother surfaces that are not overfitted. In the application here the equivalent-degrees-of-freedom values were typically 3 and 7 for MAT and P-E, yielding relatively smooth surfaces, with more variability in the P-E direction than in the MAT. To understand the trade off between goodness-of-fit and the complexity of the model, we examined adjusted $\mathrm{R}^{2}$ and Akaike Information Criterion (AIC) values for individual models, as well as F-statistics for analysis-ofvariance comparisons of a particular model with a "null" model consisting of only the mean value of the charcoal data. We follow the convention in GAM development of plotting the fitted surface over the central data-rich portion of predictorvariable space [Wood, 2006].

[18] The data for the "paleo" analysis (Figure 5a) consisted of the semi-hemispheric charcoal curves smoothed with a 2000-yr window (Figure 3) and the similarly smoothed icefree, land-only MAT and P-E values (for the same latitudes spanned by the charcoal curves) stacked on top of one another, forming a 3-column $\times$ 884-row rectangular data array. (Recall 
that for the regression analyses, values of the smoothed charcoal and climate at 100-yr intervals were used.) The semihemispheric composite curves were used in this analysis to focus on the broad-scale/long-term variations in biomass burning while minimizing the impact of local factors (including, e.g., the influence of changes in vegetation) on the final model.

[19] The data for the "modern" analysis (Figure 5b) consisted of the GFED v3.1 burnt-area data on a 0.5 -degree grid [Giglio et al., 2010] and values of MAT and P-E calculated from the CRU CL 2.0 data set [New et al., 2002]. MAT values were obtained by simple averaging, while P-E values were calculated using the approach of Cramer and Prentice [Cramer and Prentice, 1988]. The periods of record do not overlap, with the GFED v 3.1 data spanning the interval 1996-2008 and the CRU CL 2.0 data representing the 19611990 long-term mean. Experiments using the CRU TS 2.1 time series data set [Mitchell and Jones, 2005] to update the 1961-1990 long-term means show that the differences in long-term means are much smaller than the spatial variations of climate that are the focus of the analysis, this temporal mismatch does not overly influence the results. The resulting data form a 3-column by 59,239-row rectangular data set.

[20] Spatial and temporal autocorrelation are an inherent feature of both the paleo and modern data sets, and this could lead to violations of the standard assumptions of independence of regression residuals. In the presence of autocorrelation, regression residuals are no longer independent and estimators (i.e., regression coefficients) are no longer minimum variance. However, they are still unbiased, and so the shape of the surfaces will be robust with respect to this particular assumption violation.

\section{Results}

\subsection{Paleo-Record of Biomass Burning}

[21] A 2000-yr smoothed curve through the long-term global composite record shows low biomass burning at the Last Glacial Maximum (LGM), increasing during the latter part of the deglaciation (14-10 ka), and continuing to increase through the Holocene (Figure 2). The width of the bootstrap confidence interval around this smoothed curve provides a measure of the robustness of the signal; the reduction in variability characteristic of the latter part of the record is influenced by the increased number of records available but also reflects the fact that climate is less variable in most regions during the Holocene. Principal components analysis shows that the global trend from low fire at the glacial maximum to high fire during the Holocene dominates the variations shown by individual charcoal records, explaining about $67.5 \%$ of the overall variability in the global data set.

[22] The initial increase in biomass burning was asynchronous between the hemispheres (Figure 3). NH biomass burning remained low until after $16 \mathrm{ka}$, but then increased steeply. The increase in biomass burning started earlier in the $\mathrm{SH}$ and then increased more gently. Both curves reach a maximum around the beginning of the Holocene. After this, the two curves diverge again. Biomass burning continued to increase gradually throughout the Holocene in the NH while there was a marked decline in the SH during the first part of the Holocene, followed by an increase through the later Holocene. The principal components analysis, however, shows that inter- hemispheric differences in the biomass burning record account for less than $10 \%$ of the overall variability in the data set (Figure 2).

[23] The global upward trend in biomass burning, and the relative timings of the initial increase after the LGM in the $\mathrm{NH}$ and $\mathrm{SH}$, are consistent with the long-term temperature trends shown by ice core records from Greenland and Antarctica (Figure 3). The gradual increase in biomass burning in the $\mathrm{SH}$ from $18 \mathrm{ka}$ onwards is synchronous with the initial phase of warming shown in the EPICA (Antarctica) temperature record and continues through to the beginning of the Antarctic Cold Reversal (ca. 14-12.5 ka). The delayed onset of increased biomass burning in the $\mathrm{NH}$ is consistent with the $\delta^{18} \mathrm{O}$ record from NGRIP (Greenland), which shows the persistence of low temperatures in Greenland until the start of the BøllingAllerød interstadial (ca $14.7 \mathrm{ka}$ ). In the transition between glacial and interglacial states, the hemispheric trends in biomass burning are consistent with a monotonic relationship between fire and temperatures in each hemisphere (as indexed by the high-latitude ice core records).

[24] Decomposing the hemispheric curves into tropical and extratropical components reveals substantially different latitudinal patterns in long-term fire history (2000-yr smoothed curve, Figure 4). The northern extratropics show a gradual increase during the Holocene, similar to the $\mathrm{NH}$ composite. In contrast, biomass burning peaked around 14$10 \mathrm{ka}$ in the northern tropics, then declined sharply to a minimum around 9-8 ka, after which it increased steeply toward the present. The peak in the northern tropics around $12 \mathrm{ka}$, corresponds to a trough in the southern tropics, while the northern tropics trough around 9-8 ka corresponds to a peak in biomass burning in the southern tropics. This peak is followed by a trough between 7 and $5 \mathrm{ka}$ and a recovery thereafter. The composite curve for the southern extratropics shows an earlier peak than southern tropics (around 11$9 \mathrm{ka}$ ), then a pattern similar to that of the $\mathrm{SH}$ composite.

\subsection{Paleofire-Climate Relationship}

[25] The differences in the long term evolution of biomass burning between latitude bands is consistent with the evolution of land climate in response to known orbital, ice sheet topography and greenhouse-gas concentration changes (purple curve Figure 4). The long-term variations of the composite biomass burning curves can be predicted from a single global function of simulated annual temperature and a moisture index given by $\mathrm{P}-\mathrm{E}$ changes, obtained by generalized additive modeling (GAM) of the charcoal records from the four zonal composite curves sampled at 50-yr intervals against similarly zonally averaged annual values of simulated climate from non-ice covered land points.

[26] The GAM-fitted surface (Figure 5a) shows a monotonic increase in fire with temperature, and explains twothirds of the overall variance of the zonal composite curves $(\mathrm{R} 2=0.66 ; \mathrm{F}=117.08 ; \mathrm{p}<0.001)$. Temperature alone accounts for most of the overall explained variance of the zonal composite curves $(\mathrm{R} 2=0.56 ; \mathrm{F} 357.7$; $\mathrm{p}<0.001$ in a GAM with MAT as the only predictor, versus $\mathrm{R} 2=0.14$; $\mathrm{F}=20.2 ; \mathrm{p}<0.001$ in a GAM with $\mathrm{P}-\mathrm{E}$ as the only predictor). The relationship with temperature is not linear: the increase in fire per unit increase in temperature is smaller under cold than under warm conditions. The relationship between change in fire and P-E is unimodal, peaking in the 
middle of the P-E range at all temperatures. Thus, under relatively dry conditions, an increase in P-E leads to increased fire whereas, under relatively moist conditions, an increase in P-E leads to decreased fire.

[27] We tested the robustness of the model by using the individual charcoal records and GCM- simulated climate values interpolated to the location and time of each charcoal sample. The resultant GAM (Figure S3) is based on 65,000 points. The shape of the resulting response surface is remarkably similar to that obtained using the stacked curves, which should be expected, given that the stacked semi-hemispheric curves of charcoal and climate could be thought of as a firststage or intermediate smoothing step. However, as also might be expected, the explained variance is lower: the $\mathrm{R}^{2}$ value is only $3.6 \%$, but the model is nonetheless still significant $(\mathrm{F}=256.9, \mathrm{p}<0.0001)$. This statistic should not be interpreted as an indication that biomass burning is independent of climate, but instead as a measure of the high sample-tosample and site-to-site variability in the charcoal data.

[28] The magnitude of the response in biomass burning to changes in temperature alone can be illustrated by fitting a model to individual zonal averages using climate data that has not been standardized. For the northern extratropics, for example, this yields a biomass burning response of 0.47 standard deviation units for a $1^{\circ} \mathrm{C}$ increase in MAT, at intermediate levels of P-E and values of MAT typical of the late Holocene. For comparison, that magnitude of response is roughly half that of the overall increase in biomass burning between glacial and Holocene conditions. The fitted surface for the "modern" data set is similar to that for the stacked charcoal data (Figure 5b), with a monotonic increase in burnt area with increasing MAT, and the highest levels of burnt area at intermediate levels of P-E $\left(\mathrm{R}^{2}=17.3 \%, \mathrm{~F}=1243.2\right.$, $\mathrm{p}<0.0000)$. The general similarity in the shapes of the response surfaces for the paleo charcoal (Figure 5a, Figure S3) and modern burnt-area (Figure 5b) data sets imply a generic relationship between biomass burning and climate, in which biomass burning increases with increasing temperature, and is higher at intermediate levels of moisture.

\section{Implications of the Paleo-Record of Fire}

[29] A simple empirical function (Figure 4 purple curve) accurately predicts 1 ) the glacial-interglacial ramp in biomass burning at a global scale, 2) the hemispheric difference in the shape of the initial increase in biomass burning (although the function predicts the northern extratropical increase ca $1 \mathrm{ka}$ earlier than the ice core record of warming or the charcoal record of increasing biomass burning), 3) the contrasting behavior of the $\mathrm{NH}$ and $\mathrm{SH}$ biomass burning curves during the Holocene (including the gradual nature of the increase in biomass burning through the Holocene in the $\mathrm{NH}$ and the gradual decline and subsequent recovery in the $\mathrm{SH}$ ), 4) the opposition in biomass burning trends in the northern and southern tropics between 12 and $7 \mathrm{ka}$, and 5) the overall form of the Holocene trends in both the northern and southern tropics. The statistical model obtained using the charcoal data for the past $21 \mathrm{kyr}$ therefore provides support for the paradigm emerging from analysis of modern observational data which shows that the impact of temperature on fire regimes is relatively straightforward with increasing temperature leading to increased fire, with the impact of moisture changes depending on initial conditions.

[30] The climate simulations reproduce the long-term evolution of high-latitude temperature during the Holocene as seen in the ice core records (Figure S2) and many other high-latitude temperature records [Kaufman et al., 2009]. This high-latitude Holocene cooling trend is opposite from the warming trend shown at lower latitudes, indicating that, on this timescale, the ice core record is a record of local (rather than hemispheric) temperature changes. There are only 18 charcoal records in our data set from north of $65^{\circ} \mathrm{N}$, and thus it is not possible to obtain a robust reconstruction of the change in biomass burning for comparison with the ice core record of the Holocene cooling trend at these latitudes. Lower latitudes show predictable patterns of climate change (Figure S2) whose effects can be seen in the composite charcoal records from the different latitude bands.

[31] The long-term changes in biomass burning since the LGM show considerable spatial and temporal complexity, yet the main patterns can be fully explained by the interplay of effects of the major climate forcings (insolation, ice sheet configuration and atmospheric composition) on climates in different latitude bands as represented by the climate model. Fire tracks the climate changes in a predictable way that is consistent with known climatic controls on biomass burning (see also [Arneth et al., 2010; Daniau et al., 2010b; Marlon et al., 2009]). The major component of variability in biomass burning over the past $21 \mathrm{kyr}$ reflects the shift from globally cold/glacial to warm/interglacial conditions. Hemispheric differences in the timing of the beginning of this climatic transition are reflected in differences in the timing of the initial increase in fire. Temperature is the dominant driver of long-term trends in biomass burning during the deglaciation, and remains the dominant influence on extratropical fire regimes during the Holocene. The influence of hydrological changes (here represented by P-E) as a driver of long-term trends during the deglaciation is limited, but becomes important in determining the long-term trends in biomass burning in tropical regions during the Holocene.

[32] Substantial millennial-scale variability is superimposed on the long-term trends in all the composite biomass-burning curves, both during the glacial-interglacial transition and in the Holocene (500-yr smoothed curves Figure 3 and 4), especially at extratropical latitudes during the glacial and in the northern tropics during the Holocene. There is inadequate information about the forcing of such variations prior to the last millennium, and therefore no such forcings were included in the experimental design of the transient simulation. Thus, the experimental design of the simulation precludes any analysis of the millennial-scale variability shown in the charcoal records. The charcoal data show that millennial-scale variations were important nonetheless on this timescale, just as they are known to have been during the past $2 \mathrm{kyr}$ [Marlon et al., 2008] and during the last glacial [Daniau et al., 2010b]. The occurrence of high-amplitude variations in the extratropics during the glacial and in the northern tropics during the Holocene is broadly consistent with independent evidence for rapid temperature changes in mid- to high-latitudes during the glacial [see, e.g., Bond et al., 1993; Sánchez Goñi et al., 2008] and variations in monsoon strength during the Holocene [see, e.g., deMenocal et al., 2000; Dykoski et al., 2005; Lézine et al., 2007]. 
[33] The contemporary global relationship between remotely sensed burnt area and climate (Figure 5b) shows a similar climate response as the paleodata (Figure 5a): a monotonic increase in fire with temperature and a unimodal relationship to the water balance that applies at all temperature levels. The similarity between these two relationships is remarkable, given the numerous differences in the underlying data sets (burnt area versus charcoal index, spatial variability versus spatiotemporal variability, contemporary land-use versus prehistoric/historic land-use, observed versus simulated climate). Furthermore, the shape of the surface obtained from both paleo-data and remotely sensed observations is highly robust - a similar form is evident in three-dimensional scatterplots, polynomial and locally weighted regression analyses (not shown).

[34] Both the paleo-record and modern observations indicate a pervasive link between fire and climate (temperature and to a lesser extent drought), and an overall increase in fire with increasing temperature. An inescapable implication of the strong dependence of biomass burning on temperature is that the risk of fire will increase in a warmer world. There are factors that could mitigate this risk, and it is therefore worth exploring the nature of possible future changes in these factors.

[35] Increases in fire due to increased temperature could be offset by changes in precipitation. However, as we have shown, the impact of increased or decreased precipitation is dependent on initial conditions: regions that are fuel-limited today will likely experience an increase in fire with increased precipitation. Such a situation can be envisaged in, e.g., areas that are predicted to have increased precipitation as a consequence of projected expansion of monsoons under future warming [Meehl et al., 2007]. At the same time, projected increases in drought in subtropical regions are likely to enhance the risk of fire. There are regions that are not fuel-limited today and for which climate projections indicate wetter conditions (e.g., high northern latitudes), and these will likely experience reduced fire. Whether this is sufficient to offset the global increase in fire in a warmer world is unclear. Some analyses based on statistical relationships between fire and environmental conditions suggest no overall change in fire in the future [e.g., Krawchuk et al., 2009] but process-based model simulations suggest that changes in precipitation are unlikely to offset temperaturedriven increases in fire [e.g., Scholze et al., 2006b; Harrison et al., 2010; Kloster et al., 2012].

[36] Increase in fire due to more favorable climate conditions in a warmer world could be offset through management. The global incidence of fire decreased during the twentieth century [Marlon et al., 2008; Wang et al., 2010] despite increasing temperatures. This could have been a result of increasing (and increasingly efficient) fire management. However, Marlon et al. [2008] have suggested, on the basis of regional differences in the timing and strength of the downturn, that the decrease in fire was due in part to landscape fragmentation as an inadvertent consequence of the expansion of large-scale agricultural practices. If this is indeed the case, a key issue is whether there is further potential for landscape fragmentation to offset climateinduced increases in fire in the future [see, e.g., Kloster et al., 2012] given that over $75 \%$ of the land area is considered to already be impacted by human activities [Ellis and
Ramankutty, 2008]. The large number of regional studies documenting increases in fires in the last two decades [e.g., Barlow and Peres, 2004; Cary, 2002; Gillett et al., 2004; Groisman et al., 2007; Kajii et al., 2002; Meyn et al., 2007; Le Page et al., 2007; Pausas et al., 2008; Soja et al., 2007; Stocks et al., 2003; Westerling et al., 2006; Williams et al., 2010] suggest that we may already have reached the point at which landscape fragmentation is not an effective means of fire suppression, and indeed these recent increases have been explicitly linked to global warming [Running, 2006; Soja et al., 2007] Indeed, projections of future fire activity by Pechony and Shindell [2010] show an increase in global fire activity with warming that is not offset by human influences on ignitions or land use.

[37] Improved understanding of the quantitative relationships between climate changes and fire regimes suggest that a warmer world will be one where fire is an even greater hazard than it is today. The development of robust tools to predict how regional fire regimes will change in the future is urgently required. Such tools will provide a firm basis for the development of new strategies for management of or adaptation to changing fire regimes.

[38] Acknowledgments. This article is a contribution to the ongoing work of the Global Palaeofire Working Group (GPWG) of the International Geosphere-Biosphere (IGBP) Cross-Project Initiative on Fire. The GPWG has been supported by the UK Natural Environment Research Council's QUEST (Quantifying and Understanding the Earth System) program. A.-L.D. was supported by a QUEST International Research Fellowship and the NERC project ACACIA. Data compilation and analysis were supported by the QUEST-DESIRE project (S.P.H.) and by the U.S. National Science Foundation Paleoclimatology (P.J.B.) and Geography and Regional Science programs (P.J.B. and J.R.M.). Version 2 of the GPWG Global Charcoal Database is available through the World Data Centre, Palaeoclimate, at NOAA-NGDC. We thank our colleagues who have made these analyses possible through their contributions to the Global Charcoal Database, particularly K. Bennett, J. Kaal, C. Kenyon, S. Lumley, T. Manabe, S. Miyoshi, R. Nishimura, and A. Ogura. We also thank Oliver Timm and Axel Timmermann for making the results of their ECBILT-CLIO simulation publicly available. This analysis was initiated at a GPWG workshop through discussions between A.-L.D., W.T., P.J.B., S.P.H, I.C.P., S.B., P.F., J.I., J.R.M and M.J.P. A.-L.D, J.R.M, M.J.P., T.I.H.-P., and S.M. S.P. H., S.M., and J.S. compiled the charcoal data. P.J.B., S.P.H., I.C.P., and A.-L.D carried out the analyses, and K.I. assisted in the analysis of the climate simulations. M.A., J.A, H.B., M.B., O.B., K.J.B., C.C., E.C., D.C., B.A.S.D., D.D’C., J.D., L.D., Z.E., D.G.G., A.G., S.H., D.J.H., S.P.H., G. H., T.G.K., F.K., L.M.K., P.K., S.K., C.L., D.M., E.M., G.M.McK., P.I. M., P.M., F.H.N., E.N., C.P., D.R., N.R., G.S.R., N.S., L.S., H.T., V.T., F. T., R.B.T., V.G.V., B.V., M.W., N.W., and Y.Z. contributed new data to the GPWG database for this paper. A.-L.D., P.J.B., S.P.H, and I.C.P. were responsible for drafts of the manuscript and all authors commented on the final version of the paper.

\section{References}

Adams, H. D., et al. (2009), Temperature sensitivity of drought-induced tree mortality portends increased regional die-off under global-change-type drought, Proc. Natl. Acad. Sci. U. S. A., 106, 7063-7066, doi:10.1073/ pnas.0901438106.

Archibald, S., et al. (2009), What limits fire? An examination of drivers of burnt area in southern Africa, Global Change Biol., 15, 613-630, doi:10.1111/j.1365-2486.2008.01754.x.

Arneth, A., et al. (2010), Terrestrial biogeochemical feedbacks in the climate system, Nat. Geosci., 3, 525-532, doi:10.1038/ngeo905.

Barlow, J., and C. A. Peres (2004), Ecological responses to El Niñoinduced surface fires inflammable tropical forests central Brazilian Amazonia: Management implications for flammable tropical forests, Philos. Trans. R. Soc. London, Ser. B, 359, 367-380, doi:10.1098/rstb.2003.1423.

Bond, G., et al. (1993), Correlations between climate records from North Atlantic sediments and Greenland ice, Nature, 365, 143-147, doi:10.1038/ $365143 \mathrm{a} 0$.

Bowman, D. M. J. S., et al. (2009), Fire in the Earth system, Science, 324, 481-484, doi:10.1126/science. 1163886 . 
Cary, G. (2002), Importance of a changing climate for fire regimes in Australia, in Flammable Australia: The Fire Regimes and Biodiversity of a Continent, edited by R. Bradstock, J. Williams, and A. M. Gill, pp. 26-46, Cambridge Univ. Press, Cambridge.

Chuvieco, E., et al. (2008), Global characterization of fire activity: Toward defining fire regimes from Earth observation data, Global Change Biol. 14, 1488-1502, doi:10.1111/j.1365-2486.2008.01585.x.

Cleveland, W. S., and S. J. Devlin (1988), Locally weighted regression: An approach to regression analysis by local fitting, J. Am. Stat. Assoc., 83, 596-610, doi:10.1080/01621459.1988.10478639.

Cramer, W., and I. C. Prentice (1988), Simulation of regional soil moisture deficits on a European scale, Nor. Geogr. Tidsskr., 42, 149-151, doi:10.1080/00291958808552193.

Daniau, A.-L., et al. (2007), Dansgaard-Oeschger climatic variability revealed by fire emissions in southwestern Iberia, Quat. Sci. Rev., 26, 1369-1383, doi:10.1016/j.quascirev.2007.02.005.

Daniau, A.-L., et al. (2010a), Testing the hypothesis of fire use for ecosystem management by Neanderthal and Upper Palaeolithic Modern Human populations, PLoS ONE, 5, e9157, doi:10.1371/journal.pone.0009157.

Daniau, A.-L., et al. (2010b), Fire regimes during the last glacial, Quat. Sci. Rev., 29, 2918-2930, doi:10.1016/j.quascirev.2009.11.008.

Defries, R., et al. (2000), A new global 1-km dataset of percentage tree cover derived from remote sensing, Global Change Biol., 6, 247-254, doi:10.1046/j.1365-2486.2000.00296.x.

deMenocal, P., et al. (2000), Coherent high- and low-latitude climate variability during the Holocene warm period, Science, 288, 2198-2202, doi:10.1126/science.288.5474.2198

Dwyer, E., et al. (2000), Global spatial and temporal distribution of vegetation fire as determined from satellite observations, Int. J. Remote Sens., 21, 1289-1302, doi:10.1080/014311600210182.

Dykoski, C. A., et al. (2005), A high-resolution, absolute-dated Holocene and deglacial Asian monsoon record from Dongge Cave, China, Earth Planet. Sci. Lett., 233, 71-86, doi:10.1016/j.epsl.2005.01.036.

Ellis, E. C., and N. Ramankutty (2008), Putting people in the map: Anthropogenic biomes of the world, Front. Ecol. Environ, 6, 439-447, doi:10.1890/ 070062 .

Flannery, T. (1994), The Future Eaters: An Ecological History of the Australasian Lands and People, 423 pp., Reed Books, Port Melbourne, Victoria, Australia.

Fowler, C., and E. Konopik (2007), The history of fire in the southern United States, Hum. Ecol. Rev., 14, 165-176.

Galanter, M., et al. (2000), Impacts of biomass burning on tropospheric CO, $\mathrm{NO}_{X}$, and $\mathrm{O}_{3}, J$. Geophys. Res., 105(D5), 6633-6653, doi:10.1029/ 1999JD901113.

Gentleman, R. C., et al. (2004), Bioconductor: Open software development for computational biology and bioinformatics, Genome Biol., 5(10), R80, doi:10.1186/gb-2004-5-10-r80.

Giglio, L., et al. (2010), Assessing variability and long-term trends in burned area by merging multiple satellite fire products, Biogeosciences, 7, 1171-1186, doi:10.5194/bg-7-1171-2010.

Gillett, N. P., et al. (2004), Detecting the effect of climate change on Canadian forest fires, Geophys. Res. Lett., 31, L18211, doi:10.1029/ 2004GL020876.

Groisman, P. Y., et al. (2007), Potential forest fire danger over northern Eurasia: Changes during the 20th century, Global Planet. Change, 56, 371-386, doi:10.1016/j.gloplacha.2006.07.029.

Harrison, S. P. et al. (2010), Fire in the Earth system, in Changing Climates, Earth Systems and Society, edited by J. Dodson, pp. 21-48, Springer, Dordrecht, Netherlands, doi:10.1007/978-90-481-8716-4_3.

Hastie, T., and R. Tibshirani (1990), Generalized Ad̄ditive Models, Chapman and Hall, New York.

Johnsen, S. J., et al. (2001), Oxygen isotope and palaeotemperature records from six Greenland ice-core stations: Camp Century, Dye-3, GRIP, GISP2, Renland and North GRIP, J. Quaternary Sci., 16, 299-307, doi: $10.1002 /$ jqs. 622

Jouzel, J., et al. (2007), Orbital and millennial Antarctic climate variability over the past 800,000 years, Science, 317, 793-796, doi:10.1126/ science. 1141038 .

Kajii, Y., et al. (2002), Boreal forest fires in Siberia in 1998: Estimation of area burned and emissions of pollutants by advanced very high resolution radiometer satellite data, J. Geophys. Res., 107(D24), 4745, doi:10.1029/ 2001JD001078.

Kaufman, D. S., et al. (2009), Recent warming reverses long-term Arctic cooling, Science, 325, 1236-1239, doi:10.1126/science.1173983.

Kloster, S., et al. (2012), The impacts of climate, land use, and demography on fires during the 21 st century simulated by CLM-CN, Biogeosciences 9, 509-525, doi:10.5194/bg-9-509-2012.
Krawchuk, M. A., et al. (2009), Global pyrogeography: The current and future distribution of wildfire, PLOS ONE, 4(4), e5102, doi:10.1371/ journal.pone.0005102.

Lavorel, S., et al. (2007), Vulnerability of land systems to fire: Interactions among humans, climate, the atmosphere, and ecosystems, Mitig. Adapt. Strategies Glob. Change, 12, 33-53, doi:10.1007/s11027-006-9046-5.

Le Page, Y., et al. (2007), Global fire activity patterns (1996-2006) and climatic influence: An analysis using the World Fire Atlas, Atmos. Chem. Phys. Discuss., 7, 17,299-17,338, doi:10.5194/acpd-7-17299-2007.

Lézine, A.-M., et al. (2007), Centennial- to millennial-scale variability of the Indian monsoon during the early Holocene from a sediment, pollen and isotope record from the desert of Yemen, Palaeogeogr. Palaeoclimatol. Palaeoecol., 243, 235-249, doi:10.1016/j.palaeo.2006.05.019.

Marlon, J. R., et al. (2008), Climate and human influences on global biomass burning over the past two millennia, Nat. Geosci., 1, 697-702, doi:10.1038/ngeo313.

Marlon, J. R., et al. (2009), Wildfire responses to abrupt climate change in North America, Proc. Natl. Acad. Sci. U. S. A., 106(8), 2519-2524, doi:10.1073/pnas.0808212106.

Marlon, J. R., et al. (2012), Long-term perspective on wildfires in the western USA, Proc. Natl. Acad. Sci. U. S. A., 109, E535-E543, doi:10.1073/ pnas. 1112839109

Meehl, G. A., et al. (2007), Global climate projections, in Climate Change 2007: The Physical Science Basis. Contribution of Working Group I to the Fourth Assessment Report of the Intergovernmental Panel on Climate Change, edited by S. Solomon et al., pp. 789-844, Cambridge Univ. Press, Cambridge, U. K.

Meyn, A., et al. (2007), Environmental drivers of large, infrequent wildfires: The emerging conceptual model, Prog. Phys. Geogr., 31(3), 287-312, doi:10.1177/0309133307079365.

Mitchell, T. D., and P. D. Jones (2005), An improved method of constructing a database of monthly climate observations and associated highresolution grids, Int. J. Climatol., 25, 693-712, doi:10.1002/joc.1181.

Mooney, S. D., et al. (2011), Late Quaternary fire regimes of Australasia, Ouat. Sci. Rev., 30, 28-46, doi:10.1016/j.quascirev.2010.10.010.

New, M., D. Lister, M. Hulme, and I. Makin (2002), A high-resolution data set of surface climate over global land areas, Clim. Res., 21, 1-25, doi:10.3354/cr021001.

Pausas, J. G., J. Llovet, A. Rodrigo, and R. Vallejo (2008), Are wildfires a disaster in the Mediterranean basin?-A review, Int. J. Wildland Fire, 17 713-723, doi:10.1071/WF07151.

Pechony, O., and D. T. Shindell (2010), Driving forces of global wildfires over the past millennium and the forthcoming century, Proc. Natl. Acad. Sci. U. S. A., 107(45), 19,167-19,170, doi:10.1073/pnas.1003669107.

Power, M. J., et al. (2008), Changes in fire regimes since the Last Glacial Maximum: An assessment based on a global synthesis and analysis of charcoal data, Clim. Dyn., 30, 887-907, doi:10.1007/s00382-007-0334-x.

Power, M. J., et al. (2010), Fire history and the Global Charcoal Database: A new tool for hypothesis testing and data exploration, Palaeogeogr. Palaeoclimatol. Palaeoecol., 291(1-2), 52-59, doi:10.1016/j.palaeo.2009.09.014.

Power, M. J., et al. (2012), Climatic control of the biomass-burning decline in the Americas after AD 1500, Holocene, doi:10.1177/ 0959683612450196 , in press.

Prentice, I. C. (2010), The burning issue, Science, 330, 1636-1637, doi:10.1126/science.1199809.

Prentice, I. C., et al. (2011), Modeling fire and the terrestrial carbon balance, Global Biogeochem. Cycles, 25, GB3005, doi:10.1029/ 2010 GB003906.

Price, C. (2009), Will a drier climate result in more lightning?, Atmos. Res., 91, 479-484, doi:10.1016/j.atmosres.2008.05.016.

R Development Core Team (2010), R: A Language and Environment for Statistical Computing, R Foundation for Statistical Computing, Vienna, Austria.

Randerson, J. T., G. R. van der Werf, L. Giglio, G. J. Collatz, and P. S. Kasibhatla (2007), Global Fire Emissions Database, Version 2 (GFEDv2.1), Oak Ridge Natl. Lab. Distrib. Active Arch. Cent, Oak Ridge, Tenn. [Available at http://daac.ornl.gov/.].

Renssen, H., et al. (2005), Simulating the Holocene climate evolution at northern high latitudes using a coupled atmosphere-sea ice-oceanvegetation model, Clim. Dyn., 24, 23-43, doi:10.1007/s00382-0040485-y.

Running, S. W. (2006), Is global warming causing more, larger wildfires?, Science, 313, 927-928, doi:10.1126/science.1130370.

Sánchez Goñi, M. F., et al. (2008), Contrasting impacts of DansgaardOeschger events over a western European latitudinal transect modulated by orbital parameters, Quat. Sci. Rev., 27, 1136-1151, doi:10.1016/ j.quascirev.2008.03.003. 
Scholze, M., et al. (2006a), A climate change risk analysis for world ecosystems, Proc. Natl. Acad. Sci. U. S. A., 103(35), 13,116-13,120, doi:10.1073/pnas.0601816103.

Scholze, M., et al. (2006b), A climate-change risk analysis for world ecosystems, Proc. Natl. Acad. Sci. U. S. A., 103, 13,116-13,120, doi:10.1073/pnas.0601816103.

Soja, A. J., et al. (2007), Climate-induced boreal forest change: Predictions versus current observations, Global Planet. Change, 56(3-4), 274-296, doi:10.1016/j.gloplacha.2006.07.028.

Stacklies, W., et al. (2007), pcaMethods-A bioconductor package providing PCA methods for incomplete data, Bioinformatics, 23, 1164-1167, doi:10.1093/bioinformatics/btm069.

Stocks, B. J., et al. (2003), Large forest fires in Canada, 1959-1997, J. Geophys. Res., 108(D1), 8149, doi:10.1029/2001JD000484.

Timm, O., and A. Timmermann (2007), Simulation of the last 21,000 years using accelerated transient boundary conditions, J. Clim., 20, 4377-4401, doi:10.1175/JCLI4237.1.

Turner, R., et al. (2008), Climatic pacing of Mediterranean fire histories from lake sedimentary microcharcoal, Global Planet. Change, 63, 317-324, doi:10.1016/j.gloplacha.2008.07.002 van der Werf, G. R., et al. (2004), Continental-scale partitioning of fire emissions during the 1997 to 2001 El Niño/La Niña period, Science, 303, 73-76, doi:10.1126/science.1090753.

van der Werf, G. R., et al. (2008), Climate controls on the variability of fires in the tropics and subtropics, Global Biogeochem. Cycles, 22, GB3028, doi:10.1029/2007GB003122.

Wang, Z., et al. (2010), Large variations in Southern Hemisphere biomass burning during the last 650 years, Science, 330, 1663-1666, doi:10.1126/science. 1197257 .

Westerling, A. L., et al. (2006), Warming and earlier spring increase western US forest wild- fire activity, Science, 313, 940-943, doi:10.1126/ science. 1128834

Williams, A. P., et al. (2010), Forest responses to increasing aridity and warmth in the southwestern United States, Proc. Natl. Acad. Sci. U. S. A., 107, 21,289-21,294, doi:10.1073/pnas.0914211107.

Wood, S. N. (2006), Generalized Additive Models: An Introduction with R, 391 pp., CRC Press, Boca Raton, Fla. 